\title{
Synthesis and Controllable Growth Dynamics of Third Order Nonlinear Optical Material of 2-Amino-4-Methylpyridinium 2-Chloro 4-Nitro Benzoate Electro-Mechanical Investigation and Device Fabrication
}

\author{
Kuppan Venkatesan 1,2 , Lakshmanan Jothi ${ }^{3 *}$ \\ ${ }^{1} \mathrm{PG}$ and Research Department of Physics, Sri Vidya Mandir Arts and Science College, Uthangarai, India \\ ${ }^{2}$ Periyar University, Palkalai Nagar, Salem, India \\ ${ }^{3} \mathrm{PG}$ and Research Department of Physics, Namakkal Kavignar Ramalingam Government Arts College for Women, Namakkal, \\ India \\ Email: ^jothilakshmanan@gmail.com
}

How to cite this paper: Venkatesan, $\mathrm{K}$. and Jothi, L. (2021) Synthesis and Controllable Growth Dynamics of Third Order Nonlinear Optical Material of 2-Amino-4-Methylpyridinium 2-Chloro 4-Nitro Benzoate Electro-Mechanical Investigation and Device Fabrication. Journal of Minerals and Materials Characterization and Engineering, 9, 407-431. https://doi.org/10.4236/jmmce.2021.95028

Received: June 28, 2021

Accepted: August 23, 2021

Published: August 26, 2021

Copyright $\odot 2021$ by author(s) and Scientific Research Publishing Inc. This work is licensed under the Creative Commons Attribution International License (CC BY 4.0).

http://creativecommons.org/licenses/by/4.0/ (c) (i) Open Access

\begin{abstract}
An organic nonlinear optical material 2-Amino-4-methylpyridinium 2-chloro 4-nitro benzoate (AMPCNB) was synthesized and large size single crystals were grown by slow evaporation solution growth method. Single crystal X-ray diffraction study showed that the title compound belongs to monoclinic crystal system with $\mathrm{P} 2_{1} / \mathrm{n}$ space group. A powder XRD study was performed to ascertain its phase. The UV-VIS-NIR study was performed to investigate the transparency window and lower cutoff wavelength of the compound, no absorption has been observed between 318 and $1100 \mathrm{~nm}$. The third harmonic efficiency of the title compound has been studied using the Z-scan technique using continuous-wave Nd:YAG laser to confirm its saturable absorption and self-defocusing effect. The photo conducting and charge transport properties are analyzed using photoconductivity and dielectric measurements. Theoretical calculation of molecular polarizability, which is helpful in device fabrication, was carried out from Penn gap, Clausius-Mosotti equations and the obtained results were compared. Mechanical properties of the grown crystal were investigated by Vicker's microhardness study.
\end{abstract}

Keywords

Crystal Growth, Single Crystal XRD Z-Scan Studies, Photoconductivity, 


\section{Introduction}

Due to their potential applications in communication, electro-optical modulation, photo refractivity, optical storage, harmonic generation, terahertz wave generation and detection, optical switching, signal processing, and laser remote sensing, organic charge transfer, Nonlinear Optical (NLO) materials have played a significant role in the development of photonics in recent years [1] [2] [3]. Organic molecules provide increased nonlinear optical characteristics in cost-effective way due to their molecular flexibility [4]. In general, NLO activity was high in an electron conjugated moiety substituted by an electron donor group on one end and an electron acceptor group on the other end of the conjugated structure [5].

The $\pi$-electron moiety supplies the desired route over the entire length of conjugation under the influence of an applied electric field. In addition, the donor and acceptor groups supported a unique approach to proton transfer between acidic and basic organic linkages in a variety of cation-anion mixes, resulting in ground state charge asymmetry in the product molecules, which is critical for its function [6] [7].

In general, carboxylic acids possess the ability to form expected supramolecular structures with hydrogen bonding arrangements among themselves, they grabbed considerable attention as attractive substrates for organic synthesis [8] [9]. Pyridine molecule has been generally used in the formation of molecular building blocks in NLO materials as pyridine acts as cationic bonding site and nitrogen proceeds as a proton acceptor, thus suitable as an organic base [10]. The addition of a pyridine ring to NLO materials increased the number of -electrons, which resulted in a significant improvement in NLO behaviour [11].

Recent investigations on pyridine and their derivatives such as 2,6-diaminopy-ridinium 4-nitrophenolate-4-nitro phenol (DAPNP), 2-amino-4-picolinium 4-aminobenzoate, 4-dimethylamino-N-methyl-4-stilbazolium tosylate (DAST), 2-amino4-methylpyridinium-4-methoxy benzoate, 2-amino 5-chloropyridinium 4-carboxybutanoate, 2-amino-5-chloropyridinium-L-Tartrate and 2-amino 5-bromopyridinium-L-Tartrate have been reported to exhibit excellent nonlinear optical properties shows their significant role especially in the field of optical communications and frequency conversion applications [12] [13] [14].

By taking a proton $\left(\mathrm{H}^{+}\right)$from 2-chloro 4-nitro benzoic acid, the pyridine-based cation 2-amino-4-methyl pyridine (AMP) created a $\pi$-donor-acceptor molecular complex. The formed 2-amino-4-methylpyridinium 2-chloro 4-nitro benzoate (AMPCNB) compound consists of benzoate anion and protonated 2-amino-4-methylpyridine cation. From the information collected, in this present study, we have investigated the single-crystal X-ray diffraction, powder X-ray diffraction, Optical transmittance, Z-scan, Optical limiting, photoconductivity, dielectric and me- 
chanical properties of the title compound [15] [16] [17].

\section{Experimental Details}

\subsection{Material Synthesis and Microanalysis}

The salt of the title compound 2-Amino-4-methylpyridinium 2-chloro 4-nitro benzoate $\left(\mathrm{C}_{13} \mathrm{H}_{12} \mathrm{ClN}_{3} \mathrm{O}_{4}\right)$ was obtained by adding commercially purchased (Merck, AR grade > 99\%) 2-amino 4-methyl pyridine of one mole and one mole of 2-chloro 4-nitro benzoic acid in ethanol solvent. The two solutions were mixed together and stirred for about 4 hours to get a homogeneous solution, which then turned in to a form of white colored precipitate settled at the bottom of container was separated from solution and dried at $40^{\circ} \mathrm{C}$ [18] [19]. Also, the synthesized material purity was enhanced by repeated recrystallization processes using ethanol as a solvent [20].

The reaction mechanism of 2-amino-4-methylpyridinium 2-chloro 4-nitro benzoate (AMPCNB) is shown in Figure 1(a). The proportion of Carbon-HydrogenNitrogen (CHN) elemental composition of AMPCNB crystals was evaluated using Vario EL III Elemental analyzer (Germany) using helium as a carrier gas. Table 1 shows the findings of the analysis. The results obtained were in close accord with the theoretical values, confirming the presence of the chemical, as shown in the table. The schematic diagram of AMPCNB single crystal is as shown in Figure 1 (b).

\subsection{Nucleation and Crystal Growth}

The solubility study of AMPCNB was obtained using ethanol solvent for various saturation values of temperature employing conventional isothermal method by maintaining the cooling rate of $2^{\circ} \mathrm{C}$ per hour. A saturated solution of the title chemical was made at $30^{\circ} \mathrm{C}$ and placed in a bath with a programmable temperature controller to monitor and control the temperature. To eliminate the existence of spurious nuclei throughout the development process, the solution was preheated to $5^{\circ} \mathrm{C}$ above its saturation temperature for roughly 24 hours before the cooling process began. After that, the temperature of the equilibrium-saturated solution was gradually decreased to $30^{\circ} \mathrm{C}$ at a rate of $3^{\circ} \mathrm{C} / \mathrm{h}$ until a first produced small crystal (called a nucleation site) was detected. The temperature of equilibrium-saturated solution was then slowly reduced to $30^{\circ} \mathrm{C}$ with a cooling rate of $3^{\circ} \mathrm{C} / \mathrm{h}$ until a first formed tiny crystal (considered as a nucleation site) was observed [21].

Table 1. CHN Analysis of AMPCNB.

\begin{tabular}{cccc}
\hline & Nitrogen (\%) & Carbon (\%) & Hydrogen (\%) \\
\hline Experimental & 13.6132 & 50.5131 & 3.9781 \\
Theoretical & 13.5691 & 50.4230 & 3.9110 \\
\hline
\end{tabular}




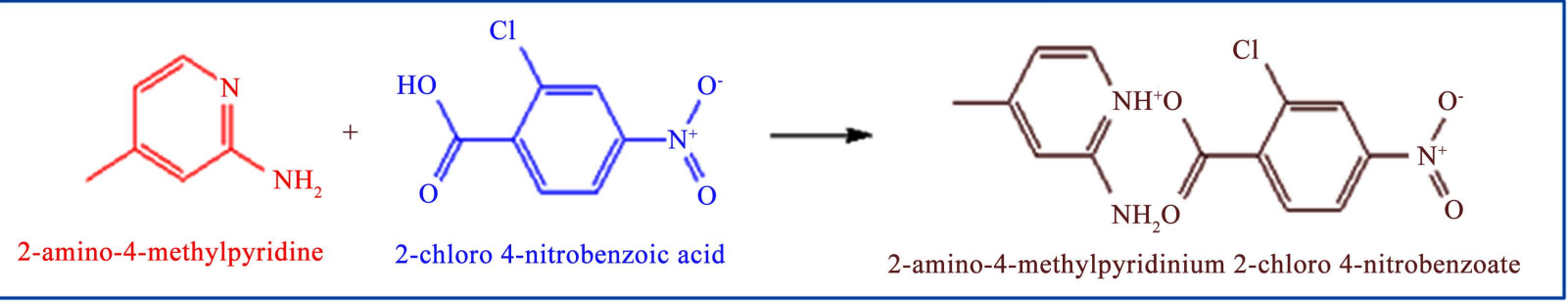

(a)

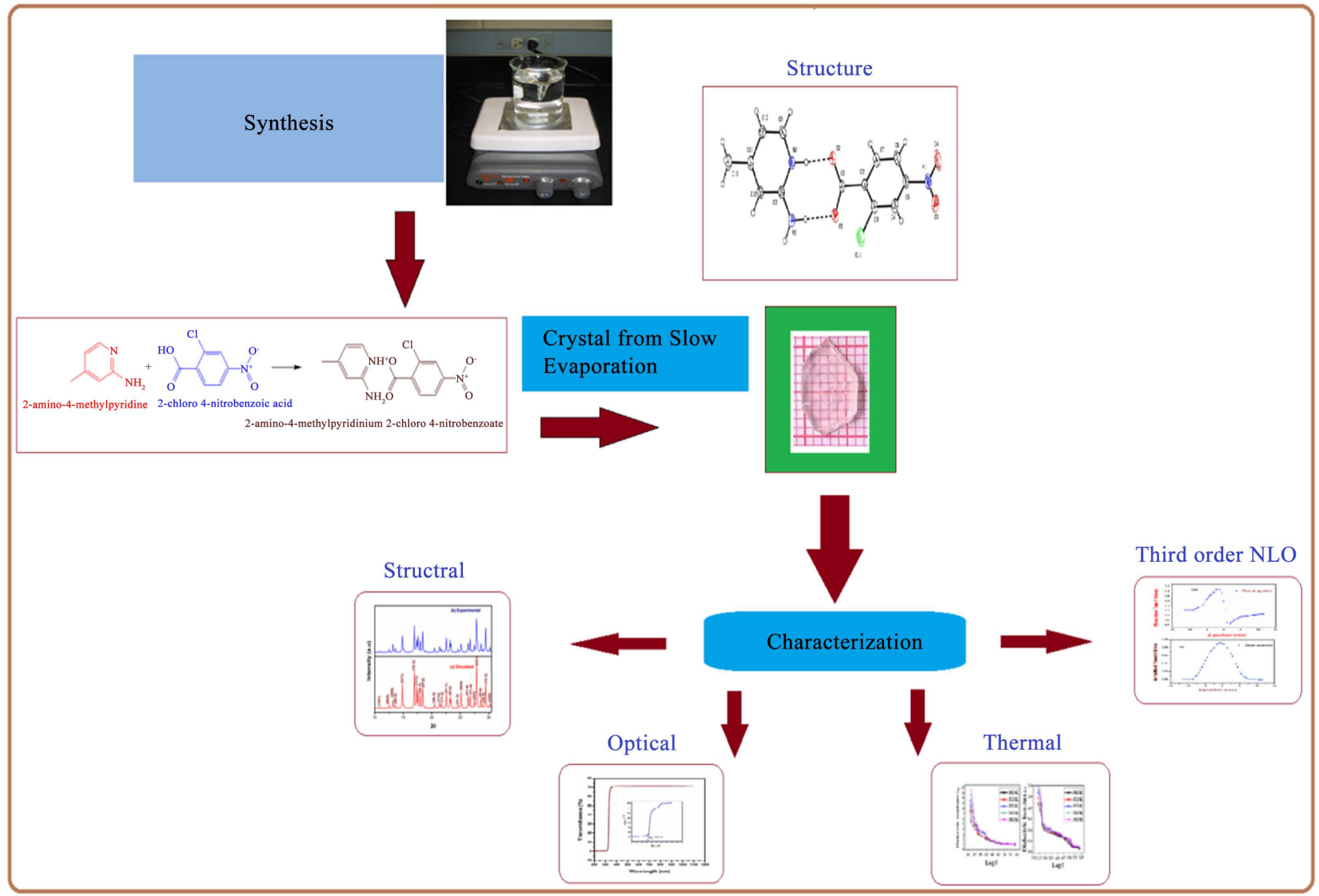

(b)

Figure 1. (a) Reaction mechanism of AMPCNB single crystal; (b) Schematic diagram of AMPCNB single crystal.

\subsection{Characterization}

In order to establish that the grown crystal was essentially AMPCNB, a tiny single crystal obtained from spontaneous nucleation process was then subjected to single crystal X-Ray Diffraction method using Enraf-Nonius CAD-4 diffractometer employed with $\mathrm{Cu}-\mathrm{K} \alpha$ radiation $(\lambda=0.71073 \AA)$ in the $2 \theta$ range $10^{\circ}-79.96^{\circ}$ at a scan rate of $0.05^{\circ} / \mathrm{sec}$, at ambient temperature. The unit cell parameter determination of AMPCNB crystal was carried out by least-squares technique employing many reflections. The structural refinement of the compound was characterized using full-matrix least-squares method via SHELXL97. The UV-VIS-NIR transmission spectrum of AMPCNB crystal was recorded using the JASCO V-630 model spectrophotometer (wavelength accuracy $\pm 0.2 \mathrm{~nm}$ ) [22]. The Jobin Yvon 
Fluorometer FL3-11 was used to record emission and absorption spectra of the material at atmosphere temperature. The instrument Metricon model 2010/M at wavelength of $632 \mathrm{~nm}$ was used to measure the refractive index of title compound [23]. Z-scan experiments were carried out on bulk materials utilizing a continuous wave Nd:YAG laser beam $(=1064 \mathrm{~nm})$ as an excitation source, which was focused using a lens with a focal length of roughly $3.5 \mathrm{~cm}$. The crystal sample was transferred along the axial direction of a focused laser beam through the focal region $(+z$ to $-z)$ in this investigation [24]. To get data regarding nonlinear absorption, open aperture Z-scan was used to get intensity dependent absorption without installing an aperture at the detector. To acquire a nonlinear refractive index, a closed aperture approach measures transmitted energy when an aperture is placed at a far field point. With the help of a digital power meter, a photo-detector through aperture gathered concentrated laser beam sent through the sample and measured its intensity [25] [26].

Using an HHVc cryostat (model-CMT-25) and a Keithley source meter, the photoconductivity behaviour of an AMPCNB single crystal was investigated (model-6487 Picometer). A well-polished (10 - 1) plane of suitably cut and polished single crystal was used for the photoconductivity experiment. The photocurrent measurement with the KEITHLEY 6487 Picoammeter uses the tungsten filament of the Halogen lamp as a source. With electric field values ranging from 0 to 100 $\mathrm{V}$, dark current values for the sample were recorded. When the sample was exposed to the irradiation of a $50 \mathrm{~W}$ halogen lamp with iodine vapour, however, photocurrent values were observed. Using a Hioki LCR 3532-50 LCR meter, dielectric studies $\left(\varepsilon_{\mathrm{r}}\right.$ and $\tan \delta$ ) of AMPCNB were carried out in the frequency range $50 \mathrm{~Hz}-5 \mathrm{MHz}$ at various temperatures. In order to provide good ohmic contact, a crystalline sample of typical size of about $6 \times 6 \times 4 \mathrm{~mm}^{3}$ was selected and a pair of polished flat surface of (10-1) \& (-101) crystal planes were coated with silver paste. To act as a parallel plate capacitor, sample (dielectric medium) is inserted between two copper electrodes [27].

The hardness of the produced crystals was investigated utilizing an LEITZ WETZLAR instrument connected to an incident light microscope and equipped with a Vicker's hardness pyramidal indenter. Crack and inclusion free single crystals of typical size of $11 \times 10 \times 7 \mathrm{~mm}^{3}$ were chosen for the hardness assessment of AMPCNB. The volume of crystal and surface area are $0.723 \mathrm{~cm}^{3}$ and $5.131 \mathrm{~cm}^{2}$, respectively. The formed crystal was suitable attached on the microscope's base, and indentations on the surface were created by increasing the applied load from $25 \mathrm{~g}$ to $100 \mathrm{~g}$. The average diagonal lengths of the indented imprints were measured using an optical microscope after five indentations were performed for each weight.

\section{Results and Discussion}

\subsection{X-Ray Diffraction Studies}

The single crystal X-ray diffraction data of the title compound were collected at 
$293 \mathrm{~K}$ with graphite-monochromated Mo K $\alpha$ radiation $(\lambda=0.71073 \AA)$, and used Enraf-Nonius CAD- 4 diffractometer with the $\omega-2 \theta$ scan mode. A suitable sample of size $0.31 \mathrm{~mm} \times 0.24 \mathrm{~mm} \times 0.15 \mathrm{~mm}$ was chosen and mounted on the goniometer. The Lattice parameters were collected from least-squares fit of many reflections. Cell refinement and data reduction were carried out using CAD-4 EXPRESS. The structures were solved using the SHELXS97 programme and refined using full-matrix least-squares on F2 using the SHELXL-97 programme. The experimental density $\left(\rho_{\mathrm{e}}\right)$ of the title compound was compared with the theoretical density $\left(\rho_{\mathrm{t}}\right)$, and the density of AMPCNB was calculated from the expression:

$$
\rho_{\mathrm{e}}=\frac{M Z}{N V}
$$

where $M$ is the molar mass, $V$ is the volume of the unit cell and $Z$ is the number of molecules in a single unit cell of the compound [28]. The comparatively good agreement between experimental and theoretical density data values $\left(\rho_{\mathrm{e}}=\right.$ $1.484 \mathrm{Mg} / \mathrm{m}^{3} ; \rho_{\mathrm{t}}=1.468 \mathrm{Mg} / \mathrm{m}^{3}$ ) showed purified nature of the grown crystal. The title compound crystallized in monoclinic space group $\mathrm{P} 2_{1} / \mathrm{n}$. The unit cell parameters for the crystal of AMPCNB are, $a=15.00134$ (1) $\AA, b=6.4361$ (4) $\AA$, $c=15.23156(10) \AA$ and $\alpha=90^{\circ}, \beta=116.157, \gamma=90$ with unit cell volume equal to $1320.88 \AA^{3}$ and the number of molecules in unit cell was 4 [29]. The ORTEP (Oak Ridge Thermal-Ellipsoid Plot Program) diagram with atom numbering scheme of the AMPCNB crystal structure was shown in Figure 2. Table 2 shows the crystal data and structure refinement of AMPCNB compound.

The planes of various reflections in powder X-ray diffraction data were indexed using mercury software. The indexed powder X-ray diffraction pattern using Mercury software and the experimentally obtained single crystal XRD data are shown in Figure 3(a) and Figure 3(b). The obtained experimental XRD pattern was compared and agreed well with the simulated XRD pattern [30].

\subsection{Solubility Studies}

The crucial parameters for the effective development, optimization, and scale-up of a crystallization process are solubility curves. The solubility measurement of a

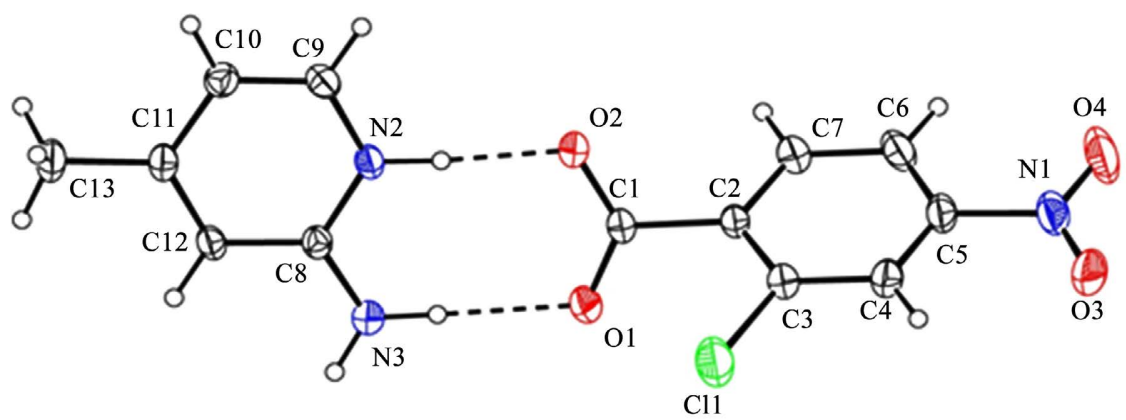

Figure 2. ORTEP diagram with atom numbering scheme of the AMPCNB crystal structure. 


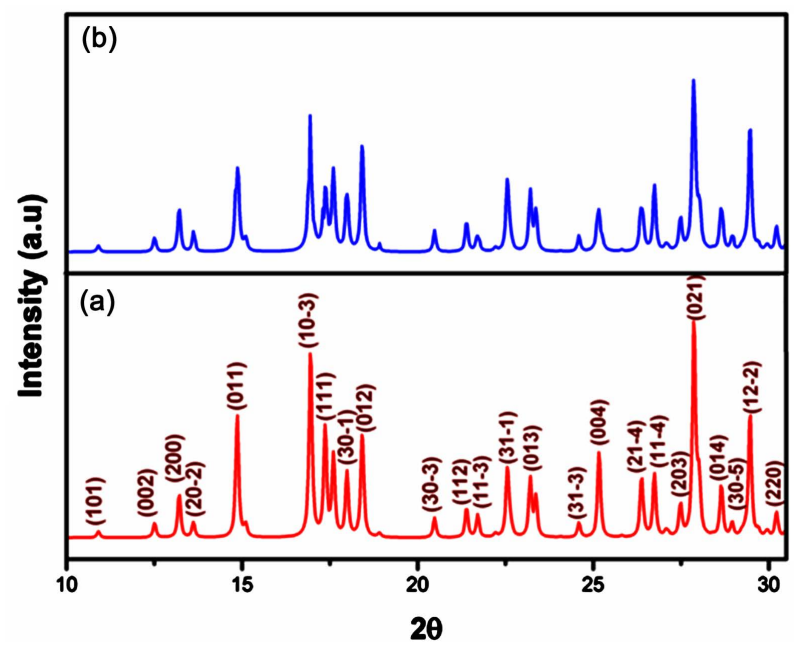

Figure 3. (a) Single crystal XRD, simulated; (b) Powder XRD plot of AMPCNB, experimental.

Table 2. Crystal data and structure refinement of AMPCNB.

\begin{tabular}{|c|c|c|}
\hline Empirical Formula & $\mathrm{C}_{13} \mathrm{H}_{12} \mathrm{ClN}_{3} \mathrm{O}_{4}$ & \\
\hline Formula weight & 309.71 & \\
\hline Temperature & $294 \mathrm{~K}$ & \\
\hline Wavelength & $0.71073 \AA$ & \\
\hline \multirow[t]{2}{*}{ Crystal system, space group } & MONOCLINICP $_{1} / \mathrm{n}$ & \\
\hline & $a=15.00134(1) \AA$ & $\alpha=90.000^{\circ}$ \\
\hline \multirow[t]{2}{*}{ Unit cell dimensions } & $b=6.4361(4) \AA$ & $\beta=116.157(1)^{\circ}$ \\
\hline & $c=15.23156(10) \AA$ & $v=90.000^{\circ}$ \\
\hline Volume & $1320.00 \mathrm{~A}^{3}$ & \\
\hline Z, Calculated density & $4,1.558 \mathrm{Mg} / \mathrm{m}^{3}$ & \\
\hline Absorption coefficient & $0.310 \mathrm{~mm}^{-1}$ & \\
\hline $\mathrm{F}(000)$ & 640 & \\
\hline Crystal size & $0.31 \times 0.24 \times 0.15 \mathrm{~mm}^{3}$ & \\
\hline Theta range & 2.5 to $28.313 \mathrm{deg}$. & \\
\hline Limiting indices & $\begin{array}{c}-10 \leq h \leq 9,-12 \leq k \leq 12 \\
-10 \leq 1 \leq 10\end{array}$ & \\
\hline Reflections collected & $5459 / 2361[\mathrm{R}(\mathrm{int})=0.035]$ & \\
\hline Completeness to $\theta=28.5^{\circ}$ & $99 \%$ & \\
\hline Refinement method & Full-matrix least-squares on $\mathrm{F}^{2}$ & \\
\hline Data/restraints/parameters & $2451 / 0 / 168$ & \\
\hline Goodness-of-fit on $\mathrm{F}^{\wedge} 2$ & 1.048 & \\
\hline Final $\mathrm{R}$ indices & $\mathrm{R} 1=0.0561, \mathrm{wR} 2=0.1677$ & \\
\hline $\mathrm{R}$ indices (all data) & $\mathrm{R} 1=0.0561, \mathrm{wR} 2=0.1677$ & \\
\hline Largest diff. peak and hole & 0.204 and $-262 \mathrm{e} \cdot \mathrm{A}^{-3}$ & \\
\hline
\end{tabular}


material in any solvent gives indication about the nucleation and availability of the solute material for crystal growth and to decide the cooling rate during the crystal growth. Super saturation is the driving force for the crystallization and it also affects the crystal quality. For growing good quality crystals the solubility of the material should be moderate. From solubility studies, it could be observed that, solubility of the compound in ethanol solvent increases linearly with increase in temperature. Also, positive solubility response of the title compound indicated the possibility of growing large size single crystals via slow cooling and slow evaporation solution growth method [31].

The variation in solubility at various temperatures is shown in Figure 4(a). Using above solubility data, bright, transparent and colorless single crystals with average dimension of about $10 \times 5 \times 6 \mathrm{~mm}^{3}$ of AMPCNB $\left(\mathrm{C}_{13} \mathrm{H}_{12} \mathrm{ClN}_{3} \mathrm{O}_{4}\right)$ were obtained. Figure 4(b) and Figure 4(c) shows the grown crystal and morphology of the mentioned compound.

\subsection{UV-Vis Spectroscopic Studies}

As transmission range and transparency cutoff are most important parameters for NLO crystals, the UV-VIS-NIR spectra were recorded for the crystals in the wavelength region from 200 to $1100 \mathrm{~nm}$ using the JASCO V-630 model spectrophotometer. The UV-VIS-NIR transmittance spectrum of title compound is

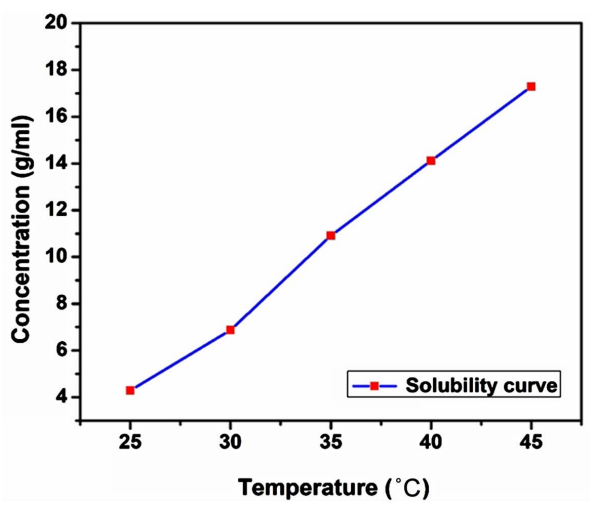

(a)

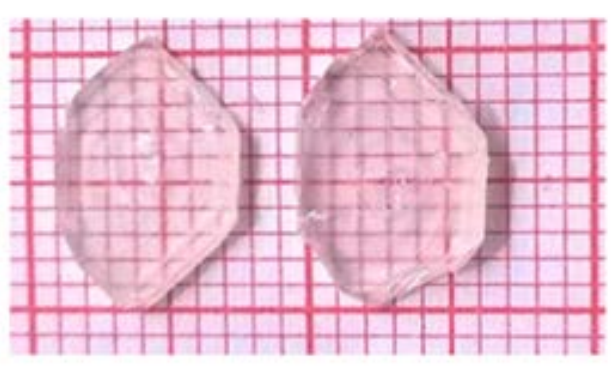

(b)

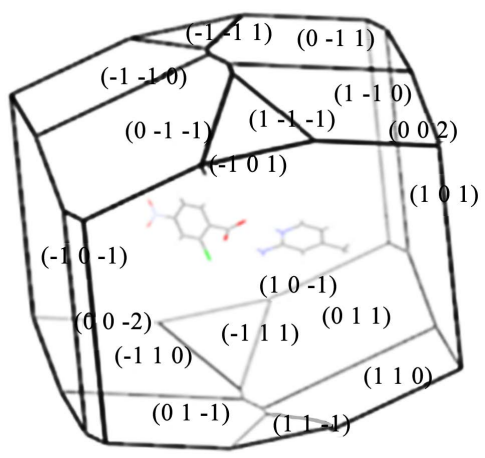

(c)

Figure 4. (a) Solubility plot of AMPCNB compound; (b) As grown crystal; (c) Morphology of AMPCNB. 
shown in Figure 5(a). The lower cutoff wavelength of AMPCNB was observed at $318 \mathrm{~nm}$, due to electron excitation transition from non-binding " $\mathrm{n}$ " orbital to antibonding " $\pi$ " orbital represented as $\pi^{\star}\left(n \rightarrow \pi^{\star}\right)$. From the plot, no absorption has been observed between 318 and $1100 \mathrm{~nm}$. In addition, maximum transparency of about 71\%, which indicated AMPCNB crystal, could be useful for NLO applications [32].

The optical absorption coefficient $(\alpha)$ was calculated by using the transmittance $(T)$ and thickness $(d)$ values of the crystal using the following relation:

$$
\alpha=\frac{2.303}{d} \log \left(\frac{1}{T}\right)
$$

Owing to the direct band gap of the AMPCNB crystal, absorption coefficient $(\alpha)$ obeying the relation for high photon energies $(h v)$ is given by:

$$
(\alpha h v)^{n}=A\left(E_{g}-h v\right)
$$

where $E_{g}$ is optical band gap of the crystal and $A$ is a constant. The plot of variation of $(\alpha h v)^{1 / 2}$ vs $(h v)$ is shown in Figure 5(b) (as inset). By extrapolating the linear portion of the curve near the start of absorption edge, the optical band gap energy of the crystal was found to be $3.61 \mathrm{eV}$. As a consequence of this wide band gap, the grown AMPCNB crystal is expected to have high damage threshold and large transmittance in the visible region [33] [34].

\subsection{Z-Scan Studies}

The analysis of NLO property in bulk materials, the Z-scan experiment were executed using continuous wave Nd:YAG laser beam $(\lambda=1064 \mathrm{~nm})$ as an excitation source and it was focused using a lens with focal length of about $3.5 \mathrm{~cm}$. A photo-detector through aperture collected focused laser beam transmitted through the sample and measured its intensity with the help of a digital power meter [35].

The plot of closed aperture setup and open aperture set up of AMPCNB as shown in Figure 6(a) and Figure 6(b). The measurable quantity $\Delta T_{p-v}$, is the difference between the peak transmittance and valley transmittance values, $T_{p}-T_{v}$ and is a function of $|\Delta \phi|$ is given by:

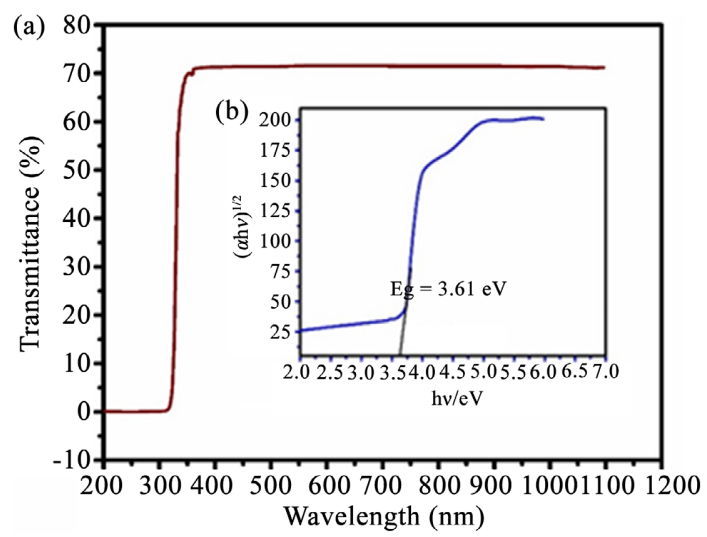

Figure 5. (a) UV-Vis-NIR transmittance spectrum; (b) Band gap plot (Inset) of AMPCNB. 


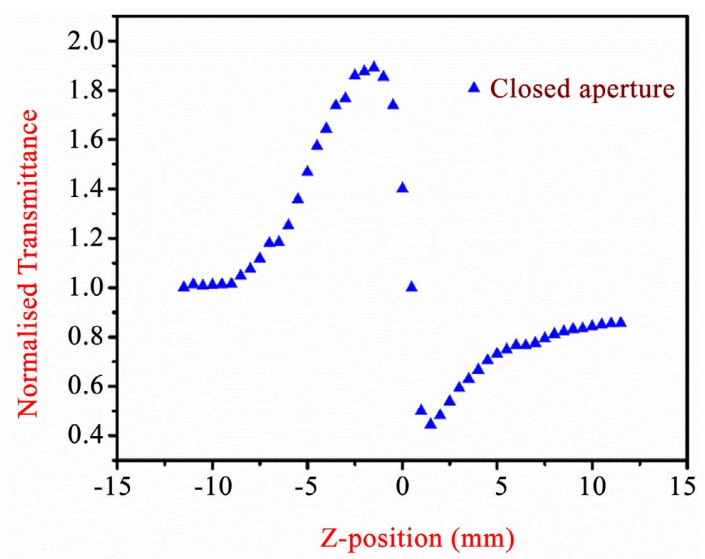

(a)

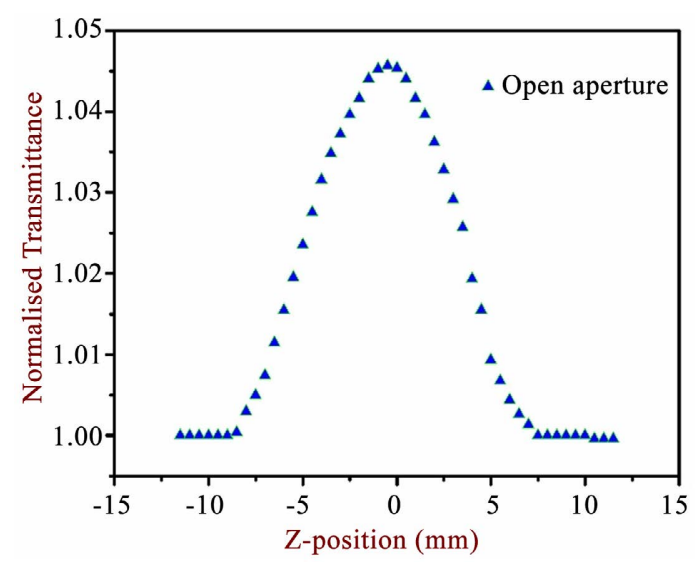

(b)

Figure 6. (a) Closed aperture Z-scanplot of AMPCNB; (b) Open aperture Z-scan plot of AMPCNB.

$$
\Delta T_{p-v}=0.406(1-S)^{0.25}|\Delta \phi|
$$

where $\Delta \phi$ is the on-axis phase shift and $S$ is the linear aperture transmittance and it is given by:

$$
S=1-\exp \left[\frac{-2 r_{a}^{2}}{\omega_{a}^{2}}\right]
$$

where $r_{a}$ is the radius of aperture and $\omega_{a}$ is the beam radius at the aperture. The on axis phase shift $(\Delta \phi)$ is related to the third order nonlinear refractive index $\left(n_{2}\right)$ :

$$
n_{2}=\frac{\Delta \phi}{k I_{0} L_{e f f}}
$$

where $k=2 \pi / \lambda, \lambda$ is the wavelength of laser beam used:

$\alpha$ is the linear absorption coefficient;

$L$ is the thickness of the specimen;

$I_{0}$ is the on-axis irradiance at focus $\left(4.38 \mathrm{KW} / \mathrm{cm}^{2}\right)$.

$L_{\text {eff }}=[1-\exp (-\alpha L)] / \alpha$, is the effective thickness of the specimen: 


$$
L_{e f f}=\frac{1-\mathrm{e}^{-\alpha L}}{\alpha}
$$

Figure 6(b), shows the Z-scan data related to open aperture arrangement $(\mathrm{S}=$ 1) of the crystalline sample. The higher transmittance value at focus exhibited the saturated behavior of absorption at higher values of intensity [36]. In closed aperture Z-scan arrangement, due to the saturation behavior of the sample, the peak increased and the valley decreased, as a result symmetry nature of Z-scan curve got changed around $\mathrm{Z}=0$ [37].

From Open aperture Z-scan set up, the nonlinear absorption coefficient can be determined as:

$$
\beta=\frac{2 \sqrt{2} \Delta T}{I_{0} L_{\text {eff }}} \mathrm{cm} / \mathrm{W}
$$

Herein $\Delta T$ is one valley value at the open aperture Z-scan plot. The real and imaginary parts of the third order nonlinear optical susceptibility could be determined from the experimental calculation of $n_{2}$ and $\beta$ according to the following relations:

$$
\begin{aligned}
& \operatorname{Re} \chi^{(3)}(\mathrm{esu})=10^{-4} \frac{\varepsilon_{o} C^{2} n_{o}^{2} n^{2}}{\pi}\left(\frac{\mathrm{cm}}{\mathrm{W}}\right) \\
& \operatorname{Im} \chi^{(3)}(\mathrm{esu})=10^{-2} \frac{\varepsilon_{o} C^{2} n_{o}^{2} \lambda \beta}{4 \pi^{2}}\left(\frac{\mathrm{cm}}{\mathrm{W}}\right)
\end{aligned}
$$

The absolute value of $\chi^{(3)}$ was calculated from the following relation.

$$
\left|\chi^{(3)}\right|=\left[\left(\operatorname{Re} \chi^{(3)}\right)^{2}+\left(\operatorname{Im} \chi^{(3)}\right)^{2}\right]^{\frac{1}{2}}
$$

The calculated nonlinear refractive index $\left(n_{2}\right)$, nonlinear absorption coefficient $(\beta)$ and third order susceptibility $\left(\chi^{(3)}\right)$ values of AMPCNB single crystal are $5.610 \times 10^{-8} \mathrm{~cm}^{2} / \mathrm{W}$ and $0.033 \times 10^{-4} \mathrm{~cm} / \mathrm{W}$ and $2.942 \times 10^{-6}$ esu respectively [38]. The value of the nonlinear refractive index indicates the self-defocusing nature of the compound which clearly shows the title compound exhibit negative nonlinear optical properties [39] [40]. The nonlinear absorption exhibited by the specimen could be attributed to its saturation absorption process and this could make the title compound useful for optical limiting applications [41] [42]. The third order nonlinear properties of AMPCNB crystal are provided in Table 3.

\subsection{Photoconductivity Studies}

The photoconductivity behavior of AMPCNB single crystal was examined using HHVc cryostat of model-CMT-25 with Keithley source meter of model-6487 Picometer. The applied electric field was increased from 10 to $100 \mathrm{~V} / \mathrm{cm}$. All the measurements were taken at room temperature. The sample was protected from all the illuminations and the corresponding dark current was recorded. The electric field dependent photoconductivity study could be an effective method, in which 
Table 3. Third order nonlinear properties of AMPCNB crystal.

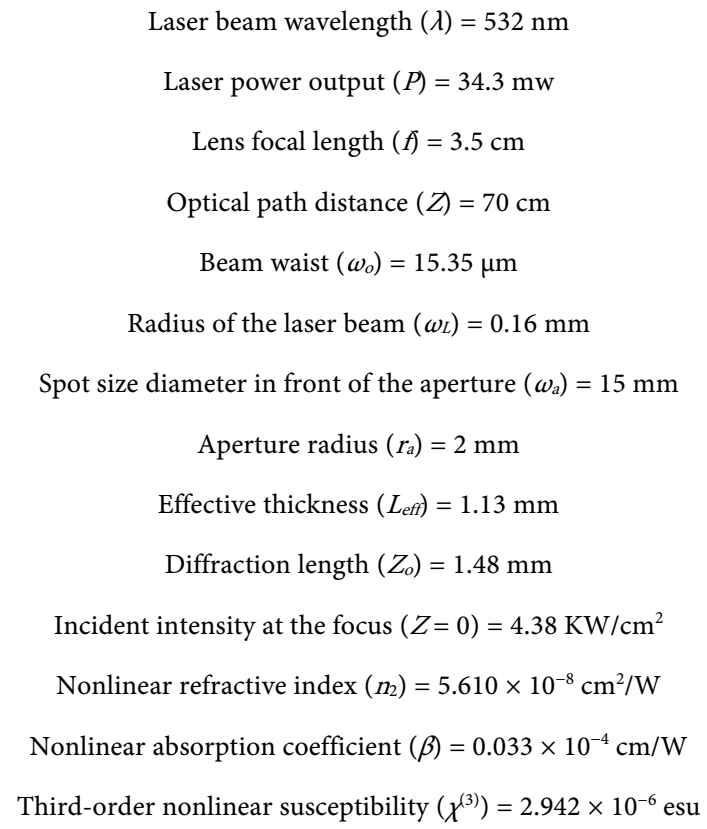

conversion of laser pulses (picosecond) of low energy in to electric pulses of comparatively higher order were produced. From Figure 7, the linear response of photoconductivity plot (both photocurrent and dark current) against applied field of AMPCNB at $300 \mathrm{~K}$ was observed. Also, recorded higher photo current response than dark current values of the sample under investigation showed direct excitation of charge carriers to appear in higher energy levels (intrinsic center formation) and lack of traps [43] [44].

The positive conductivity nature established generation of mobile charge carriers when photons were absorbed by the sample. The increase in photocurrent and dark current values could be attributed to the generation of large number of charge carriers (electron-hole pairs) when the sample is exposed to stream of photons of energy $E>E_{g}$ ( $E_{g}$ is band gap energy) [45] [46]. Further, crystals possessed large band gap for photon absorption could be useful in the field of soliton wave communication, where optical pulses pass through longer distances in photonic band gap without any distortion [47].

\subsection{Dielectric Studies}

The dielectric characteristics of materials are crucial for understanding charge transport events and crystal lattice dynamics. The dielectric behaviour of AMPCNB single crystals was investigated using the HIOKI 3532-50 LCR Hi-TESTER at temperatures ranging from $303 \mathrm{~K}$ to $343 \mathrm{~K}$ in the frequency range of $50 \mathrm{~Hz}-5 \mathrm{MHz}$. The growing AMPCNB was sliced into rectangular dimensions and dielectric experiments were performed on it. The opposing faces of the crystals were covered with electronic grade silver paint to form electrical contacts, and the electrical contacts were obtained [48]. 


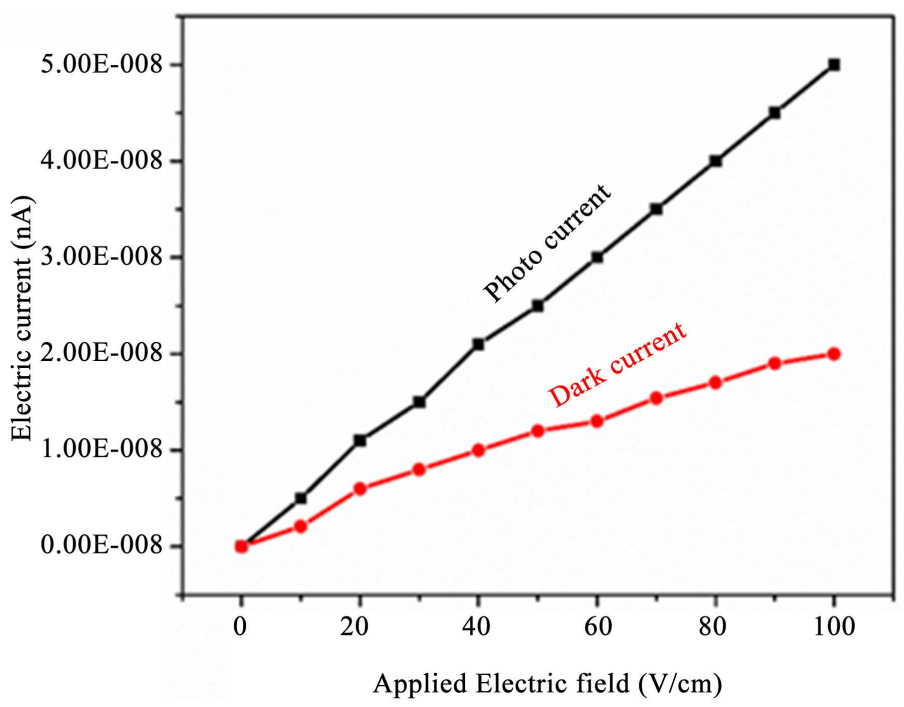

Figure 7. Photo current and dark current response of AMPCNB.

The dielectric constant was calculated using the formula:

$$
\varepsilon_{r}=\frac{C t}{A \varepsilon_{o}}
$$

The variation of $\log$ frequency against dielectric constant at various temperatures is shown in Figure 8(a). From figure it could be seen that there is exponential decrease in $\mathcal{E}_{r}$ with increase in frequency and linear increase in $\varepsilon_{r}$ at lower frequency region, revealed contribution of various polarization mechanisms in a solid material [49]. The highest value of dielectric constant $\left(\varepsilon_{r}=11.4\right)$ at temperature, $T=343 \mathrm{~K}$ was observed at lower frequencies, $(f=500 \mathrm{~Hz})$ could be due to the contribution from all the four types of polarization mechanisms (electronic, ionic, orientation and space charge polarization) [50]. Since, AMPCNB possessed domains of various sizes and differing relaxation times, dielectric constant and loss values decreased gradually with increase in frequency values. The stable low value of dielectric constant, $\mathcal{E}_{r}=0.79$ at temperature, $T=343 \mathrm{~K}$ was observed at $f$ $=5 \mathrm{MHz}$ frequency showed the major contribution of electronic polarization.

In addition, the lower values of dielectric constant of AMPCNB at higher frequencies indicated the material could possibly exhibit relatively low power dissipation behavior as like other organic NLO crystals, such as NSP, B2AM, 4APM, L-arginine acetate, 4-methyl benzophenone and 2-amino-5-chloro pyridine [51]. Comparision of $\varepsilon_{\mathrm{r}}$ values of different pyridine derivative crystals at $T=343 \mathrm{~K}$ is shown in Table 4. The same trend was observed in the measurement of dielectric loss values as a function of frequency and temperature (Figure 8(b)). At lower frequency region, material exhibited higher values of dielectric loss due to space charge polarization [52]. The increase in applied electric field frequency decrease polarization and, as a result dielectric loss values are decreased. The larger value of dielectric loss ( $\tan \delta=2.38$ ) for the title compound is observed for a frequency of $500 \mathrm{~Hz}$ at temperature, $T=343 \mathrm{~K}$. However smaller value of loss 


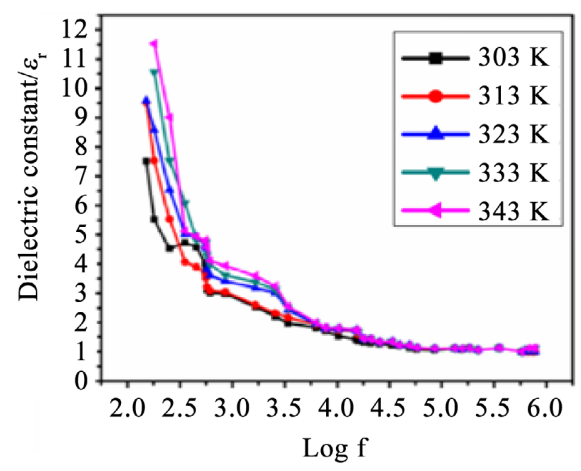

(a)

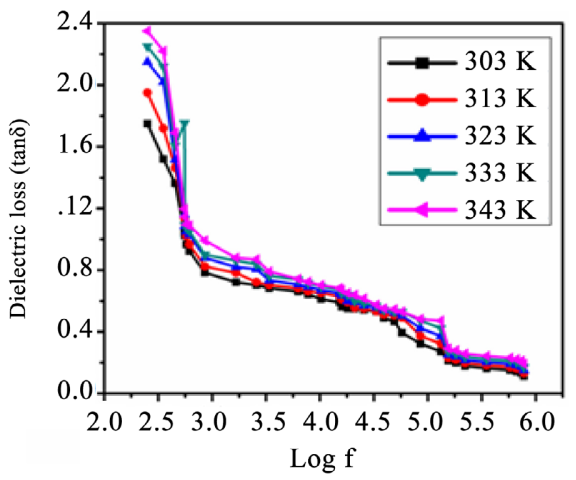

(b)

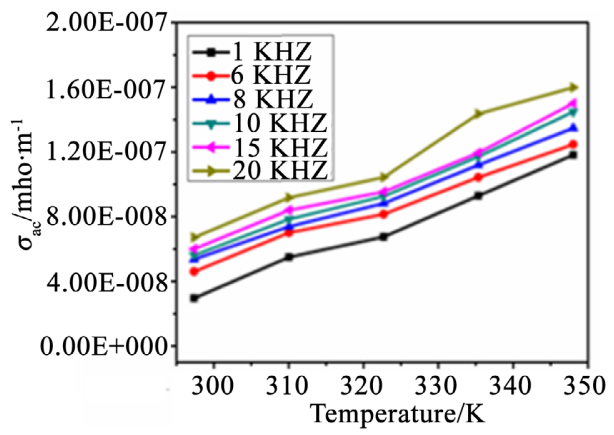

(c)

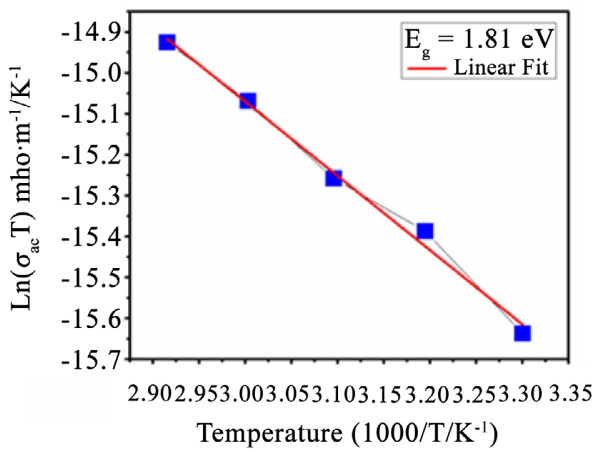

(d)

Figure 8. (a) Variation of Dielectric constant $\left(\varepsilon_{\mathrm{r}}\right)$ as a function of Log frequency at different temperatures; (b) Variation of Dielectric loss $(\tan \delta)$ as a function of Log frequency at different Temperatures; (c) Variation of Ac conductivity as a function of Log Frequency at various temperatures; (d) Activation Energy of AMPCNB crystal. 
Table 4. Comparision of dielectric constant values of different pyridine derivatives.

\begin{tabular}{ccc}
\hline Pyridine derivative & $\begin{array}{c}\text { Dielectricconstant } \\
\left(\varepsilon_{r}\right) \text { at } 343 \mathrm{~K}\end{array}$ & Reference \\
\hline 2-amino-4-methylpyridinium 2-chloro 4-nitro benzoate & 11.5 & Present work \\
2-amino-5-chloropyridinium-4-carboxybutanoate & 9.4 & {$[40]$} \\
2-aminomethylpyridinium picrate & 38 & {$[40]$} \\
4-aminopyridinium p-amino benzoate & 420 & {$[40]$} \\
Dimethyl amino pyridinium 4-nitro phenolate & 1180 & {$[40]$} \\
\hline
\end{tabular}

$(\tan \delta=0.18)$ is observed for $5 \mathrm{MHz}$ frequency at $343 \mathrm{~K}$, showed AMPCNB crystal could be a suitable candidate for photonic, optoelectronic and NLO applications [53]. The variation in dielectric loss and dielectric constant with the change in frequency confirmed the title compound under investigation possessed dipoles with continuously varying relaxation times which are not responded to higher frequencies [54]. Further, lower values of dielectric constant at higher frequencies ascertained the presence of lesser number of electrically active defects in the crystal, which facilitated its use in NLO applications [55]. Arrhenius plot drawn between $\ln \sigma_{a c} T$ and 1000/ $T$ for grown AMPCNB crystal is shown in Figure 8(c). From the figure, it could be observed that, ac conductivity noticeably increases with temperature.

The line of best fit for the plot of $\ln \sigma_{a c} T$ and $1000 / T$ obeys Arrhenius relationship:

$$
\sigma_{a c}=\sigma_{o} \exp \left(\frac{-E_{a c}}{k T}\right)
$$

where $\sigma_{o}$ is pre-exponent factor, $E_{a c}$ is the activation energy for the ionic conduction process, $k$ is Boltzmann constant and $T$ is the temperature. Hence, crystal under investigation shows Arrhenius type of conductivity behavior in the above said range of temperature. The calculated activation energy of title compound from Figure 8(d) due to thermally activated charge transfer process was found to be $1.81 \mathrm{eV}$, which indicated smaller defect numbers in the title compound [56].

\section{Theoretical Evaluation of Plasma Energy, Penn Gap and Fermi Energy and Polarizability}

In general, NLO efficiency of a nonlinear optical single crystal is strongly influenced by its electronic properties, thus it is essential to investigate them in detailed manner [57]. Theoretical evaluations indicate that $\varepsilon_{r}$ at high frequency explicitly depends on valence electron plasma energy, Fermi energy and an average energy gap indicate to as Penn gap energy. From the fitting of dielectric constant with Plasmon energy, Penn gap is evaluated for the title crystal.

The valence electron Plasma energy ( $\left.\hbar \omega_{p}\right)$ of AMPCNB is given by:

$$
\hbar \omega_{p}=28.8 \times\left(\frac{Z_{\rho}}{M}\right)^{1 / 2}
$$


where $Z=\left(\left(13 Z_{C}\right)+\left(12 Z_{H}\right)+\left(3 Z_{N}\right)+\left(1 Z_{c l}\right)+\left(4 Z_{O}\right)\right)=160$ is number of total valence electrons, $M$ is molecular weight and $\rho$ is density of the crystal.

The Penn gap and Fermi energy are given by:

$$
\begin{gathered}
E_{P}=\left(\frac{\hbar \omega_{p}}{\varepsilon_{\infty}-1}\right)^{1 / 2} \\
E_{F}=0.2948(\hbar \omega p)^{4 / 3}
\end{gathered}
$$

Molecular Polarizability $(\alpha)$ is calculated using the relation:

$$
\begin{gathered}
\alpha=\left[\frac{\left(\hbar \omega_{p}\right)^{2} S_{o}}{\left(\hbar \omega_{p}\right)^{2} S_{o}+3 E_{P}^{2}}\right] \times\left(\frac{M}{\rho}\right) \times 0.396 \times 10^{-24} \mathrm{~cm}^{-1} \\
S_{o}=1-\left[\frac{E_{F}}{4 E_{F}}\right]+\frac{1}{3}\left[\frac{E_{F}}{4 E_{F}}\right]^{2}
\end{gathered}
$$

The calculated value of $\alpha$ from penn gap closely agree with that of the ClausiusMosotti relation:

$$
\alpha=\frac{3 M}{4 \pi N_{a} \rho}\left(\frac{\varepsilon_{\infty}-1}{\varepsilon_{\infty}+2}\right)
$$

All the calculated values of AMPCNB are compared with KDP and 2A5BPTA crystals and listed in Table 5 . It is found that the polarizability value of the title compound is comparable with KDP and 2A5BPTA [58].

\subsection{Micro Hardness Studies}

In a crystalline material all the mechanical behavior is highly influenced by its chemical composition and structure. Since, mechanical properties of a material played major role in device fabrication, properties of materials like fracture behavior, brittleness index, yield strength and temperature of cracking can be determined by micro hardness testing method [59]. In general, hardness is a measure of resistance offered by the material to local deformation.

Among different types of hardness test methods available, Vicker's hardness technique is the most suitable method employed for testing hardness property of

\begin{tabular}{|c|c|c|c|}
\hline Parameters & $\begin{array}{l}\text { Values for AMPCNB } \\
\text { (Present work) }\end{array}$ & $\begin{array}{c}\text { Values for 2A5BPTA } \\
\text { [43] }\end{array}$ & $\begin{array}{c}\text { Values for KDP } \\
\text { [43] }\end{array}$ \\
\hline Plasma energy (eV) & 18.42 & 21.24 & 17.28 \\
\hline Penn gap energy $(\mathrm{eV})$ & 5.559 & 6.132 & 2.37 \\
\hline Fermi energy $(\mathrm{eV})$ & 13.92 & 17.344 & 12.02 \\
\hline Polarizability by Penn analysis & $5.431 \times 10^{-23}$ & $5.419 \times 10^{-23}$ & $2.14 \times 10^{-23}$ \\
\hline By Clausius-Mosotti relation & $5.433 \times 10^{-23}$ & $5.415 \times 10^{-23}$ & $2.10 \times 10^{-23}$ \\
\hline
\end{tabular}
electroplated thin layers and brittle materials having tendency for fracture, proportional to volume of loaded material. Hardness is one of the mechanical properties to determine the plastic nature, fracture behavior, molecular bindings and

Table 5. Theoretical parameters of AMPCNB. 
yield strength of the material [60]. The hardness of AMPCNB was measured by LEITZ WETZLAR instrument attached with Vicker's hardness pyramidal indenter to an incident light microscope.

The Vickers hardness number $\left(H_{V}\right)$ of grown crystal was calculated using the following relation:

$$
H_{v}=1.8554\left(\frac{P}{d^{2}}\right)\left(\mathrm{kg} / \mathrm{mm}^{2}\right)
$$

where $H_{V}$ is the Vickers hardness number in $\mathrm{Kg} / \mathrm{mm}^{2}, P$ is the applied load in $\mathrm{Kg}$, and $d$ is the average diagonal length of the indented impression in $\mathrm{mm}$.

The calculated values of $H_{V}$ as a function of different loads are plotted in Figure 9(a). Maximum value of load applied to the grown crystal was $100 \mathrm{~g}$, further increase in load above $100 \mathrm{~g}$ micro cracks were observed around the region of impression due to the release of internal stress generated locally by a deformation. For this reason readings were not taken for maximum loads. It is also obvious from the figure that hardness value increases with increase in load and the crystal exhibited reverse Indentation Size Effect (ISE). Reverse ISE of grown crystals shows increase in hardness values with increase in the value of applied load compared with the normal ISE [61]. The plot of $\log P$ against $\log d$ indicated linear response.

The relationship between load $(P)$ and diagonal length $(d)$ (Figure 9(b)) from Meyer's law:

$$
P=a d^{n}
$$

where, " $n$ " is Meyer's Index or work hardening coefficient. The value of " $n$ " could be calculated from the slope of a straight line using least-square fitting method. The obtained value of $n=2.77$ is also compared with other pyridine derivatives, such as NSP, 4APM, B2APM, which exhibit Meyer's index $(n)$ values, $3.449,3.1$ and 3.56 respectively [62].

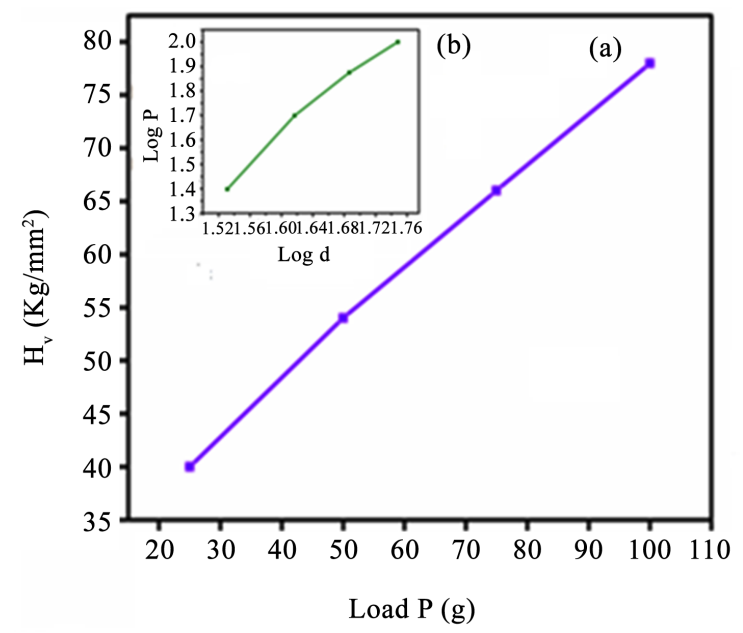

Figure 9. (a) Hardness profile of AMPCNB single crystal against Vickers indentation; (b) Log P versus Log d (inset). 
Onitsch pointed out that, materials having $n<2$ are considered as hard materials and with $n>2$ are considered as soft materials. In practice, $H_{V}$ increases with increasing load for soft materials and decreases with increasing load for hard materials, so it is apparent (Figure 10(a)) that the title compound crystal belongs to the soft material category. Further, the elastic stiffness constant of single crystal was determined from Wooster's formula [63].

The law related Elastic stiffness coefficient and Vicker's Hardness number as:

$$
C_{11}=\left(H_{v}\right)^{7 / 4}
$$

Measurement of elastic coefficient of the single crystal sample revealed tightness of bonding between adjacent atoms and also featured the rate of variation of the forces of attraction and repulsion between the atoms in the sample. Figure 10 indicates the variation of elastic stiffness coefficient with applied load in $\mathrm{Kg}$ and, Table 6 shows tightness of binding forces between atoms in the material are fairly strong.

Yield strength $\left(\sigma_{y}\right)$ of the title compound was also calculated by using the values of work hardening coefficient and Vicker's hardness number [64] [65]. It is defined as the stress at which the material starts to deform plastically. Generally Yield strength depends on Meyer's index number $n$. For $n>2, \sigma_{y}$ can be computed using the following relation:

$$
\sigma_{y}=\frac{3-n}{2.9} \frac{(12.5[n-2])^{(n-2)}}{(3-n)^{(n-2)}} H_{v}
$$

For $n<2$, the yield strength can be calculated using the relation:

$$
\sigma_{y}=\frac{H_{v}}{3}
$$

Figure 11 reveals the increase in yield strength with increasing load. Table 6 displays the increase in stiffness constant and yield strength with increasing load values in AMPCNB single crystal [66].

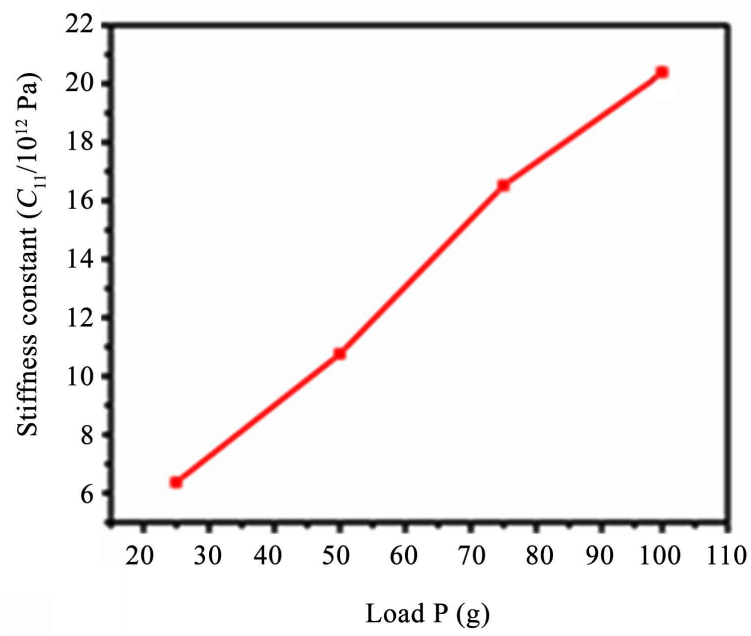

Figure 10. Stiffness constant vs Load P of AMPCNB. 


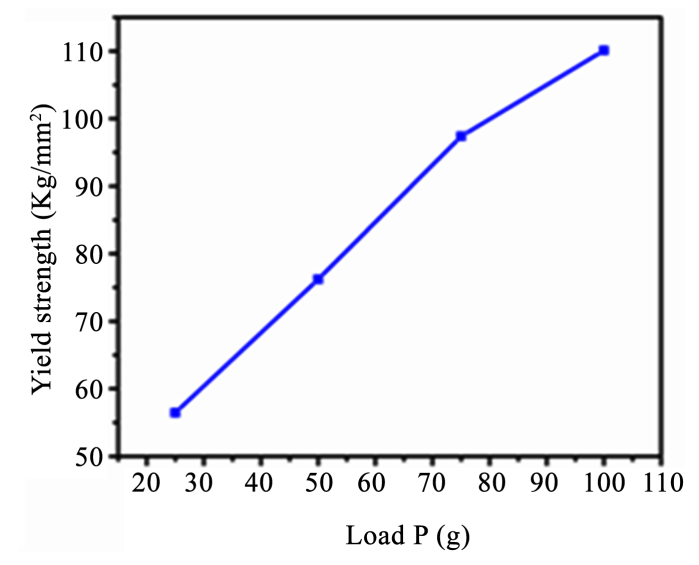

Figure 11. Yield strength vs Load P of AMPCNB.

Table 6. Stiffness constant and yield strength values of AMPCNB with load/g.

\begin{tabular}{ccc}
\hline Load/g & $\sigma_{y}$ & $C_{11} / 10^{12} \mathrm{~Pa}$ \\
\hline 25 & 6.3621 & 56.4548 \\
50 & 10.7569 & 76.21398 \\
75 & 16.5190 & 97.38453 \\
100 & 20.4722 & 110.0868 \\
\hline
\end{tabular}

\subsection{Conclusions}

The slow evaporation approach was used to successfully generate single crystals of AMPCNB. The crystal structure of the title compound was determined using the single crystal XRD method, and it was determined that the crystal belonged to the molecules crystal system with the $\mathrm{P}_{21} / \mathrm{n}$ centrosymmetric space group. The unit cell parameters for the crystal of AMPCNB are, $a=14.9230$ (9) $\AA, b=$ 6.5971 (4) $\AA, c=15.7552$ (10) $\AA$ and $\alpha=90^{\circ}, \beta=116.237^{\circ}, \gamma=90^{\circ}$ with unit cell volume equal to $1385.94 \AA^{3}$. The powdered material of the title compound was subjected to microanalysis, powder XRD to further establish the composition, crystalline phase respectively. The UV-VIS-NIR lower cut-off wavelength was found to be $318 \mathrm{~nm}$ and energy gap is $3.16 \mathrm{eV}$. The crystal's transmittance percentage is 71 , indicating that it has good optical transparency. Z-Scan studies were carried out to calculate the third order NLO coefficient of grown crystal AMPCNB, confirmed that it exhibited self-defocusing nature. The calculated nonlinear refractive index $\left(n_{2}\right)$, nonlinear absorption coefficient $(\beta)$ and third order susceptibility $\left(\chi^{(3)}\right)$ values of AMPCNB single crystal are $5.610 \times 10^{-8} \mathrm{~cm}^{2} / \mathrm{W}$ and $0.033 \times 10^{-4}$ $\mathrm{cm} / \mathrm{W}$ and $2.942 \times 10^{-6}$ esu respectively. The photoconductivity study of title compound revealed positive photoconductivity response could be employed in soliton wave communication. The low value of dielectric dispersion and dielectric loss at high frequencies propose that the sample acquries improved optical eminence with lesser defects, which facilitated its use in NLO applications. The Vicker's hardness study showed the grown crystalline material belongs to soft material category and also confirmed the reverse indentation size effect for applied loads. 
The increase in stiffness constant and yield strength with increasing load values in AMPCNB single crystal. Thus, the above mentioned studies establish that AMPCNB could act as an efficient material for NLO and opto-electronic applications.

\section{Conflicts of Interest}

The authors declare no conflicts of interest regarding the publication of this paper.

\section{References}

[1] Rajkumar, M. and Chandramohan, A. (2016) Synthesis, Spectral, Thermal, Mechanical and Structural Characterization of NLO Active Organic Salt Crystal: 3,5-Dimethylpyrazolium-3-Nitrophthalate. Materials Letters, 181, 354-357. https://doi.org/10.1016/j.matlet.2016.04.191

[2] Senthilkannan, K. and Gunasekaran, S. (2013) Spectroscopic Studies and Other Novel Studies of 4-Bromo 4'-Chloro Benzylidene Aniline (BCBA) Crystal: A Non Linear Optical Material. International Journal of Chem Tech Research, 5, 3051-3058.

[3] Anandhi, S., Rajalakshmi, M., Shyju, T.S. and Gopalakrishnan, R. (2011) Growth and Characterization of an Adduct 4-Aminobenzoic Acid with Nicotinic Acid. Journal of Crystal Growth, 318, 774-779. https://doi.org/10.1016/j.jcrysgro.2010.10.113

[4] Bronte, J., Ziller, J.W. and Heyduk, A.F. (2021) Metal-Ion Influence on Ligand-Centered Hydrogen-Atom Transfer. Inorganic Chemistry, 60, 1579-1589. https://doi.org/10.1021/acs.inorgchem.0c02981

[5] Jothi, L., Vasuki, G., Babu, R.R. and Ramamurthi, K. (2014) Synthesis, Crystal Growth and Characterization of Organic NLO Material: 4-Bromo-4-Hydroxybenzy-lidene Aniline. Optik, 125, 2017-2021. https://doi.org/10.1016/j.ijleo.2013.07.170

[6] Krishnakumar, V., Nagalakshmi, R., Manohar, S., Piasecki, M., Kityk, I.V. and Bragiel, P. (2010) Parametrical Optical Effects in the 1:1 Complex of Resorcinol and Urea-A Nonlinear Optical Crystal. Physica B: Condensed Matter, 405, 839-842. https://doi.org/10.1016/j.physb.2009.08.057

[7] Selvakumar, S. and LeoRajesh, A. (2016) Synthesis and Characterization of Organic Nonlinear Optical Material: Urea Para-Nitrophenol. Journal of Materials Science. Materials in Electronics, 27, 7509-7517.

[8] Korkmaz, U. and Bulut, A. (2015) 2-Pyridinium Propanal Hydrogen Aquarate: Experimental and Computational Study of a Nonlinear Optical Material. Spectrochimica Acta Part A: Molecular Spectroscopy, 136, 1058-1068.

[9] Dennington, R., Keith, T. and Millam, J. (2009) Gauss View, Version 5. Semichem Inc., Shawnee Mission.

[10] Glowacki, E.D., Irimia-Valadu, M. and Sariciftci, N.S. (2013) Hydrogen-Bonds in Molecular Solids-From Biological Systems to Organic Electronics. Journal of Materials Chemistry B, 1, 3724-3753. https://doi.org/10.1039/c3tb20193g

[11] Maharani, M.Y., Cyracpeter, A., Gopinath, S., Tamilvanan, S., Vimalan, M. and Potheher, I.V. (2016) Growth and Characterization of Amino Based Organic Nonlinear Optical 1-Lysine-1-Asparate (LLA) Single Crystal for Electro-Optic Application. Journal of Materials Science: Materials in Electronics, 27, 5006-5015.

[12] Muthuraj, P., Sethuram, M., Raman, M.S., Dhandapani, M. and Amirthaganesan, G. (2013) Synthesis, Spectral, Thermal, Optical, Electrical, Mechanical, and Structural Characterization and Quantum Chemical Study of 4-Nitrophenol: Urea Molecular Adduct Crystal. Journal of Molecular Structure, 1053, 5-14. 
https://doi.org/10.1016/j.molstruc.2013.09.004

[13] Saravanan, M., Senthil, A. and Rajaseker, S.A. (2015) Synthesis, Growth, Structural, and HOMO and LUMO, MEP Analysis of a New Stilbazolium Derivative Crystal: A Enhanced Third-Order NLO Properties with a High Laser-Induced Damage Threshold for NLO Applications. Optical Materials, 48, 226-232. https://doi.org/10.1016/j.optmat.2015.08.005

[14] Silambarasan, A., Rajesh, R. and Ramasamy, P. (2014) Synthesis, Growth, Structural, Optical and Thermal Properties of an Organic Single Crystal: 4-Nitroaniline 4-Aminobenzoic Acid. Spectrochimica Acta Part A: Molecular and Biomolecular Spectroscopy, 118, 24-27. https://doi.org/10.1016/j.saa.2013.08.052

[15] Arumanayagam, T. and Murugakoothan, P. (2013) Studies on Growth, Spectral and Mechanical Properties of New Organic NLO Crystal: Guanidinium 4-Nitrobenzoate (GuNB). Journal of Crystal Growth, 362, 304-307. https://doi.org/10.1016/j.jcrysgro.2011.10.063

[16] Muthuraj, P., Sethuram, M., Shanmugavadivu, T. and Dhandapani, M. (2016) Single Crystal X-Ray Diffraction and Hirshfeld Surface Analysis of Supramolecular Assemblies in Certain Hydrogen Bonded Heterocyclic Organic Crystals. Journal of Molecular Structure, 1122, 146-156. https://doi.org/10.1016/j.molstruc.2016.05.083

[17] Jothi, L., Babu, R.R. and Ramamurthi, K. (2014) Synthesis, Growth, and Characterization of Organic Nonlinear Optical Single Crystal of 4-Bromo-4'-Methyl Benzylidene Aniline. Journal of Minarals Characterization and Engineering, 2, 308-318. https://doi.org/10.4236/jmmce.2014.24036

[18] Selvakumar, E., Chandramohan, A., Babu, G.A. and Ramasamy, P. (2014) Synthesis, Growth, Structural, Optical and Thermal Properties of a New Organic Salt Crystal: 3-Nitroanilinium Trichloroacetate. Journal of Crystal Growth, 401, 323-326. https://doi.org/10.1016/j.jcrysgro.2013.10.053

[19] Jang, J. and Kim, I.W. (2016) Poly (Acrylic Acid) to Induce Competitive Crystallization of a Theophylline/Oxalic Acid Cocrystal and a Theophylline Polymorph. Journal of Crystal Growth, 434, 104-109. https://doi.org/10.1016/j.jcrysgro.2015.11.004

[20] Shanmugam, G., Ravikumar, K., Sridhar, B. and Baradeeswaran, S. (2012) Synthesis, Structure, Growth and Characterization of Novell NLO Organic Single Crystal: Morpholin-4-Ium p-Aminobenzoate. Materials Research Bulletin, 47, 2315-2323. https://doi.org/10.1016/j.materresbull.2012.05.037

[21] Peramaiyan, G., Pandi, P., Sornamurthy, B.M., Bhagavannarayana, G. and Mohan kumar, R. (2012) Growth, Structural, Thermal, Linear and Nonlinear Optical and Laser Damage Threshold Studies of Picolinium Tartrate Monohydrate Single Crystals. Spectrochimica Acta, Part A: Molecular and Biomolecular Spectroscopy, 95, 310-316. https://doi.org/10.1016/j.saa.2012.03.082

[22] Rajkumar, M., Saravanabhavan, M. and Chandramohan, A. (2017) Synthesis, Structural, Thermal, Mechanical, Second Order Harmonic Generation Efficiency and Laser Damage Threshold Studies of 4-Dimethylaminopyridinium-3,5-dicarboxy-benzoate Trihydrate Single Crystal. Optical Materials, 72, 247-246. https://doi.org/10.1016/j.optmat.2017.06.011

[23] Gayathri, K., Krishnan, P., Sivakumar, N., Kalainathan, S., Bhagavannarayana, G. and Anbalagan, G. (2014) Growth, Crystal Perfection, Optical and Electrical Properties of Organic Crystal: Brucinium 5-Sulfosalicylate Trihydrate. Optik, 125, 6881-6886. https://doi.org/10.1016/j.ijleo.2014.08.110

[24] Murugesan, V., Saravanabhavan, M. and Seker, M. (2015) Synthesis, Characterization and Pharmacological Investigation of a New Charge-Transfer Complex of 3-Ami- 
nopyridiump-Toluenesulfonate. Journal of Molecular Structure, 1084, 95-102. https://doi.org/10.1016/j.molstruc.2014.12.022

[25] Krishnakumar, V., Rajaboopathi, M. and Nagalakshmi, R. (2012) Studies on Vibrational, Dielectric, Mechanical and Thermal Properties of Organic Nonlinear Optical Co-Crystal: 2,6-Diaminopyridium-4-nitrophenolate-4-nitrophenol. Physica B, 407, 1119-1123. https://doi.org/10.1016/j.physb.2012.01.084

[26] Uma, J. and Rajendran, V. (2013) Study of Optical, Thermal and Mechanical Properties of Trisglycine Zinc Chloride: A Semiorganic Non-Linear Optical Single Crystal. Archives of Applied Science Research, 5, 208-212.

http://scholarsresearchlibrary.com/archive.html

[27] Arun, K.J. and Jayalakshmi, S. (2008) Investigation on the Nonlinear Optical Properties of Glycinium Oxalate Single Crystal. Journal of Optoelectronics and Advanced Materials, 2, 136-138.

[28] Thirupugalmani, K., Karthick, S., Shanmugam, G., Kannan, V., Sridhar, B., Nehru, N. and Brahadeeswaran, S. (2017) Second- and Third-Order Nonlinear Optical and Quantum Chemical Studies on 2-Amino-4-picolinium-nitrophenplate-nitrophenol: A Phase Matchable Organic Single Crystal. Optical Materials, 49, 79-93.

[29] Krishnakumar, M., Karthick, S., Thirupugalmani, K. and Brahadeeswaran, S. (2017) Second and Third-Order Nonlinear Optical and DFT Calculations on 2-Amino-5chloro Pyridinium-l-tartrate: A Phasematchable Organic Single Crystal. Optical Materials, 66, 79-93. https://doi.org/10.1016/j.optmat.2017.01.034

[30] Anoop, M.R., Binil, P.S., Suma, S., Sudarsankumar, M.R., Mary, Y.S., Varghese, H.T. and Panicke, C.Y. (2010) Vibrational Spectroscopic Studies and Computational Study of Ethyl Methyl Thiosemicarbanzone. Journal of Molecular Structure, 969, 48-54. https://doi.org/10.1016/j.molstruc.2010.01.041

[31] Shanmugam, G. and Brahadeeswaran, S. (2012) Spectroscopic, Thermal and Mechanical Studies on 4-Methylanilinium p-Toluenesulfonate-A New Organic Single Crystal. Spectrochimica Acta Part A, 95, 177-183. https://doi.org/10.1016/j.saa.2012.04.100

[32] Rajkumar, M. and Chandramohan, A. (2017) Synthesis, Growth, Characterization and Lase Damage Threshold Studies on N,N-dimethylanilinium-3 Carboxy-4-hydroxybenzenesulphonate Crystal: An Efficient SHG Material for Electro-Optic Applications. Optical Materials, 66, 261-270. https://doi.org/10.1016/j.optmat.2017.02.022

[33] D’silva, E.D., Podagatlapalli, D.K., Rao, S.V. and Dharmaprakash, S.M. (2012) Structural, Optical and Electrical Characteristics of a New NLO Crystal. Optics \& Laser Technology, 44, 1689-1697. https://doi.org/10.1016/j.optlastec.2012.01.017

[34] Bryndal, I., Ledoux-Rak, I., Lis, T. and Ratajczak, H. (2014) Search for Molecular Crystals with NLO Properties: 5-Sulfosalicyclic Acid with Nicotinamide and Iso-Cicotinamide. Journal of Molecular Structure, 1068, 74-83. https://doi.org/10.1016/j.molstruc.2014.03.060

[35] Girisun, T.C.S. and Dhanuskodi, S. (2009) Linear and Nonlinear Optical Properties of Tris-Thiourea Zinc Sulphate Single Crystals. Crystal Research and Technology, 12, 1297-1302. https://doi.org/10.1002/crat.200900351

[36] Bincy, I.P. and Gopalakrishnan, R. (2014) Synthesis, Growth and Characterization of New Organic Crystal: 2-Aminopyridinium p-Toluenessulfonate for Third Order Nonlinear Optical Applications. Journal of Crystal Growth, 3, 22-33. https://doi.org/10.1016/j.jcrysgro.2014.03.024

[37] Dhavamurthy, M., Peramaiyan, G. and Mohan, R. (2014) Synthesis, Growth, Structural, Optical, Thermal, Dielectric and Mechanical Studies If an Organic Guanidinium p-Nitrophenolate Crystal. Journal of Crystal Growth, 399, 13-18. 
https://doi.org/10.1016/j.jcrysgro.2014.04.013

[38] Jin, S., Lu, X. and Chen, D. (2012) Crystal and Molecular Structure of Four 1:1 Adducts from 2-Methylquinoline and Different Acidic Components. Journal of Molecular Structure, 1010, 17-25. https://doi.org/10.1016/j.molstruc.2011.11.004

[39] Alam, M.S. and Lee, D.-U. (2015) Synthesis, Crystal Structure, Hirshfeld Surfaces, Fluorescence Properties and DFT Analysis of Hydrazine Schiff Bases. Spectrochimica Acta Part A, 145, 563-574. https://doi.org/10.1016/j.saa.2015.03.071

[40] Silambarasan, A., Krishnakumar, M., Thirunavukkarasu, A., Zahid, I., Kumar, R.M. and Umarani, P.R. (2015) Studies on Growth, Spectral. Structural, Electrical, Optical and Mechanical Properties of Uranium 3-Carboxy-4-hydroxybenzenesulfonate Single Crystal for Third-Order Nonlinear Applications. Spectrochimica Acta, Part A: Molecular and Biomolecular Spectroscopy, 142, 101-109.

https://doi.org/10.1016/j.saa.2015.01.093

[41] Singh, R.K. and Singh, A.K. (2017) DFT Calculations on Molecular Structure, Spectral Analysis, Multiple Interactions Reactivity, NLO Property and Molecular Docking Study of Flavanol-2,4-dinitrophenylhydrazone. Journal of Molecular Structure, 1129, 128-141. https://doi.org/10.1016/j.molstruc.2016.09.072

[42] Rajkumar, M. and Chandramohan, A. (2017) Synthesis, Growth, Structural, Optical, Thermal, Electrical and Mechanical Properties of Hydrogen Bonded Organic Salt Crystal: Triethylammonium-3,5-dinitrosalicylicate. Journal of Molecular Structure, 1134, 762-769. https://doi.org/10.1016/j.molstruc.2017.01.034

[43] Babu, B., Chandrasekeran, A., Thirumurugan, R., Jayaramakrishnan, V. and Anitha, K. (2017) Experimental and Theoretical Investigation on 2-Amino 5-Bromopyridinium L-Tartrate-A New Organic Charge-Transfer Crystal for Optoelectronics Device Applications. Journal of Materials Science: Materials in Electronics, 28, 1124-1135.

[44] Balaji, J., Prabu, S., Sanjan, D. and Srinivasan, P. (2017) Investication on Spectroscopic, Dielectric and Optical Studies in 3-Hydroxypyridinium 4-Nitrobenzoate Crystals. Journal of Molecular Structure, 1137, 142-149. https://doi.org/10.1016/j.molstruc.2017.02.040

[45] Rajkumar, M. and Chandramohan, A. (2017) Synthesis, Crystal Structure, Physicochemical Properties of Hydrogen Bonded Supramolecular Assembly of N,N-dithylanilinium-3,5-dinitrosalicylate Crystal. Journal of Molecular Structure, 1149, 530-538. https://doi.org/10.1016/j.molstruc.2017.08.021

[46] Sakunthaladevi, R. and Jothi, L. (2021) Chemical Growth Dynamics of 4-Methyl-4-hydroxy Benzylidene Aniline NLO Single Crystal Structure and Spectroscopic Applications. Journal of Molecular Structure, 1233, Article ID: 130054.

[47] Jagedesan, A., Peramaiyan, G., Kumar, R.M. and Arjunan, S. (2015) Growth, Optical, Thermal, and Laser Damage Threshold Studies of 4-Nitrophenolate 4-Nitrophenol Crystals. Journal of Crystal Growth, 418, 153-157. https://doi.org/10.1016/j.jcrysgro.2015.02.069

[48] Saravanan, M. and Rajaseker, S.A. (2016) Growth and Characterization of Benzaldehyde 4-Nitro Phenyl Hydrazine (BPH) Single Crystal: A Proficient Second Order Nonlinear Optical Material. Optical Materials, 54, 217-218.

https://doi.org/10.1016/j.optmat.2016.02.039

[49] Mathew, V., Jacob, S., Mahadeven, C.M. and Abraham, K.E. (2011) Dielectric and Magnetic Studies of Gel-Grow Copper Malonate Trihydrate Crystals. Materials Letters, 65, 2142-2145. https://doi.org/10.1016/j.matlet.2011.04.049

[50] Shanmugam, G., Thirupugalmani, K., Rakhikrishna, R., Philip, J. and Brahadeeswaran, 
S. (2013) Thermophysical, Mechanical and Dielectric Studies on Piperidinium p-Hydroxybenzoate. Journal of Thermal Analysis and Calorimetry, 114, 1245-1254. https://doi.org/10.1007/s10973-013-3156-6

[51] Sudharsana, N., Keerthana, B., Nagalakshmi, R., Krishnakumar, V. and Prasad, L.G. (2012) Growth and Characterization of Hydroxyethylammonium Picrate Single Crystal for Third Order Nonlinear Optical Applications. Materials Chemistry and Physics, 134, 736-746. https://doi.org/10.1016/j.matchemphys.2012.03.062

[52] Potheher, I.V., Rajarajan, K., Jeyasekaran, R., Vimalan, M., Yogam, F. and Sagayaraj, P. (2013) Growth, Optical, Thermal and Conductivity Behavior of Nonlinear Optical Single Crystals of $\mathrm{CdHg}(\mathrm{SCN})_{4}\left(\mathrm{CH}_{3} \mathrm{OC}_{2} \mathrm{H}_{5} \mathrm{O}\right)$. Journal of Thermal Analysis and Calorimetry, 111, 1491-1497. https://doi.org/10.1007/s10973-012-2533-x

[53] Adegoke, A.O. (2011) Analytical, Biochemical and Synthetic Applications of Para-Dimethylaminobenzaldehyde. International Journal of Pharmaceutical Sciences Review and Research, 11, 17-29.

[54] Sinha, N., Sahas, B.K., Singh, K., Kumar, N., Singh, M.K., Gupta, G.C. and Kumar, B.B. (2009) Solution Growth and Comparative Characterization of L-HFB Single Crystals. Crystal Research and Technology, 44, 167-172. https://doi.org/10.1002/crat.200800190

[55] Shanker, V.S., Sanker, R., Siddheswaran, R., Jayavel, R. and Murugakoothanan, P. (2008) Growth and Characterization of Tetra L-Lysine Alanine Mono Hydrochloride Dehydrate (TLAMHCI), a New Semiorganic Optical Single Crystal. Materials Chemistry and Physics, 109, 119-124. https://doi.org/10.1016/j.matchemphys.2007.11.008

[56] Rani, T.D., Rajkumar, M. and Chandramohan, A. (2018) Synthesis, Crystal Structure, Thermal, Mechanical and Laser Damage Threshold Studies of an NLO Active Organic Molecular Adduct: 4-Acetylpyridine: 4-Aminobenzoicacid. Materials Letters, 222, 118-121. https://doi.org/10.1016/j.matlet.2018.03.195

[57] Sivasubaramani, V., Pandian, M.S., Boopathi, K. and Ramasamy, P. (2016) Crystal Growth, Structural, Optical, Thermal, and Dielectric Studies of Nonlinear Optical 2-Amino-5-nitropyridinium Nitrate (2A5NPN) Single Crystal. Materials Research Innovations, 22, 128-136. https://doi.org/10.1080/14328917.2016.1264859

[58] Sheldrick, G.M. (1997) Phase Annealing in SHELX-90: Direct Methods for Larger Structures. Acta Crystallographica Section A, 46, 467-473.

[59] Venkataramanan, V., Matheswaran, S., Sherwood, J.N. and Bhat, H.L. (1997) Crystal Growth and Physical Characterization of a Semiorganic Bis(thiourea) Cadmium Chloride. Journal of Crystal Growth, 173, 605-610. https://doi.org/10.1016/S0022-0248(97)00137-1

[60] Srinivasan, P., Kanagasekaran, T.K., Bhagavannarayana, G., Gopalakrishnan, R. and Ramasamy, P. (2006) Studies on the Growth and Characterization of L-Asparaginium Picrate (LASP) a Novel Nonlinear Optical Crystal. Crystal Growth \& Design, 6, 1663 1667. https://doi.org/10.1021/cg060094+

[61] Badran, H.A., Mudhaffer, M.F., Hassan, Q.M. and Ahamad, A.Y. (2012) Study of the Linear Optical Properties and Surface Energy Loss of 5',5"-Dibromo-Ocresol-sulfophthalein Thin Films. Chalcogenide Letters, 9, 483-493.

[62] Pandi, P., Peramaiyan, G., Mohan Kumar, R., Bhagavannarayanan, G. and Jayavel, R. (2013) Studies of Structural, Third Order Nonlinear Optical and Laser Damage Threshold Properties of Diethylammonium p-Hydroxybenzoate Single Crystal. Applied Physics $A, 112,711-717$. https://doi.org/10.1007/s00339-013-7763-7

[63] Wolff, S.K., Grimwood, D.J., Mckinnon, J.J., Turner, M.J., Jayatilaka, D. and Spackman, M.A. (2013) Crystal Explorer 3.1. University of Western Australia, Crawley, 2005-2013.

[64] Rajendran, V. and Uma, J. (2016) Synthesis, Structural, Topographical, Linear and Non- 
linear Optical, Electrical and Mechanical Properties of Bisthiourea Zinc Acetate Single Crystal. Optical Materials, 57, 249-256.

https://doi.org/10.1016/j.optmat.2016.05.006

[65] Vijayalakshmi, A., Balaji, V. and Vinitha, G. (2016) Structure and Characterization of a New Organic Crystal for Optical Limiting Application, Isonicotinamide Bis-paminobenzoic Acid. Ukrainian Journal of Physical Optics, 17, 98-104.

https://doi.org/10.3116/16091833/17/3/98/2016

[66] Rajkumar, R., Kamaraj, A., Bharanidharan, S., Saleem, H. and Krishnasamy, K. (2015) Synthesis, Spectral Characterization, Single Crystal X-Ray Diffraction and DFT Studies of 4-((2,4,5-triphenyl-1H-imidazol-1-1-yl)methyl) Pyridine Derivatives. Journal of Molecular Structure, 1084, 74-81. https://doi.org/10.1016/j.molstruc.2014.10.035 